\title{
Effect of Ionic Strength on the Bundling of Metal Oxide Imogolite Nanotubes
}

Erwan Paineau, ${ }^{a, *}$ Mohamed Salah Amara, ${ }^{a, b}$ Geoffrey Monet, ${ }^{a}$ Véronique Peyre, ${ }^{c}$ Stéphan Rouzière, ${ }^{a}$ Pascale Launois ${ }^{a, *}$

${ }^{a}$ Laboratoire de Physique des Solides, UMR CNRS 8502, Univ. Paris-Sud, Université ParisSaclay, Bâtiment 510, 91405 Orsay, France

${ }^{b}$ LIONS, NIMBE, CEA, CNRS, Université Paris Saclay, CEA Saclay, F-91191 Gif-sur-Yvette Cedex, France

${ }^{c}$ PHENIX, UMR CNRS 8234, Sorbonne Universités, UPMC Univ. Paris 06, 75005 Paris, France 
ABSTRACT: Significant developments have been proposed over the last decade in the synthesis of aluminosilicate and aluminogermanate imogolite-like nanotubes. But, while liquid phase synthesis is well controlled, it is not the case for an imogolite or imogolite-like nanotube arrangement in dry state. In particular, nanotubes are found to self-assemble in bundles of various sizes, which may impact the properties of the final product. Here, we investigate the effect of ionic strength on bundling of aluminogermanate single-walled imogolite nanotubes (Ge-SWINT) in aqueous suspensions and in the resulting powders after solvent evaporation. The nanotube arrangement as a function of salt concentration was studied by X-ray scattering experiments and simulations. In aqueous suspension, nanotubes bundling occurs only at high ionic strength (IS $>8 \times 10^{-2} \mathrm{~mol} \cdot \mathrm{L}^{-1}$ ) while beyond this threshold, the increase of electrostatic repulsions induces a complete stabilization of individual nanotubes. After solvent evaporation, nanotube arrangement is shown to be dictated principally by the initial concentration of salt. Beyond an ionic strength of $\sim 10^{-3} \mathrm{~mol} \cdot \mathrm{L}^{-1}$ in the starting suspension, all Ge-SWINT samples tend to form large bundles in powder, whose lattice parameter are independent of the initial salt concentrations. These experimental results clearly show that the positive surface charge of imogolite can be used to control nanotubes bundling by anion condensation. 


\section{INTRODUCTION}

Studies related to nanotubes represent actually an entire part of nanosciences and nanotechnology research. This interest rises since the early 90 's with carbon nanotubes $(\mathrm{CNT})^{1}$ and the succeeding synthesis of a wide variety of inorganic ones. ${ }^{2,3}$ The world-wide excitement for these iconic objects that are CNTs has certainly shed light on clay nanotubes. In particular, imogolite nanotubes (INT), first recognized in weathered volcanic soils as true hollow aluminosilicate tubes thirty years before the emergence of $\mathrm{CNTs},{ }^{4,5}$ appear as the only inorganic nanotube equivalent to single walled (SW) CNTs in terms of diameter.

INT has a nominal composition $(\mathrm{OH})_{3} \mathrm{Al}_{2} \mathrm{O}_{3} \mathrm{Si}(\mathrm{OH})$, which is also the sequence of atoms encountered on passing from the outer to the inner surface of the nanotube, and is constructed from a curved gibbsite-like $\mathrm{Al}(\mathrm{OH})_{3}$ layer on which isolated $\left[(\mathrm{OH}) \mathrm{SiO}_{3}\right]$ tetrahedral units are bonded upright to octahedral vacancies (Figure 1), thereby forming a single-walled (SW) structure with an external diameter of $2 \mathrm{~nm} .{ }^{5}$ Farmer et al. were the first to propose, in 1977, a synthetic route to achieve INT in aqueous suspension and under low-temperature conditions, using a simple hydrolysis step of a solution of aluminum and silicon precursors. ${ }^{6}$ Since then, several synthetic routes have been explored to increase the yield of the synthetic products. ${ }^{7-10}$ Among them, a major breakthrough in the last decade arises from the substitution of silicon by germanium. ${ }^{11}$ This leads to the synthesis of concentrated (molar) suspensions of single- or double-walled (DW) aluminogermanate nanotubes with larger external diameters, typically $\sim 4$ nm. ${ }^{9,12}$

More recently, Fe-doped INT have also been explored by isomorphic substitution of $\mathrm{Al}^{3+}$ by $\mathrm{Fe}^{3+}$ in order to bring magnetic properties in these nanostructures. ${ }^{13,14}$ Finally, both inner and outer hydroxylated surfaces offer interesting possibilities for surface functionalization. INTs can 
thus be rendered amphiphilic by replacing their inner silanol or germanol moiety by a functionalized one,${ }^{15}$ or by grafting molecular compounds on the outer aluminum wall. ${ }^{15-18}$ Whatever the nature ( $\mathrm{SW}$ or DW) or the nanotube nominal composition $(\mathrm{OH})_{3} \mathrm{Al}_{2} \mathrm{O}_{3} \mathrm{Si}_{\mathrm{x}} \mathrm{Ge}_{1}$ ${ }_{x}(\mathrm{OH})$, INTs remain monodisperse in diameter and chirality, a feature ascribed to a unique minimum in the strain energy of the structure. ${ }^{19,20}$ These recent developments have paved the way for novel imogolite-like nanotubes with fine control of their morphologies and properties either by atomic substitution, ${ }^{21-23}$ by changing the nature of precursors, ${ }^{9,24,25}$ or the synthesis temperature. ${ }^{26}$ Therefore, imogolite-like nanotubes could find applications in a wide range of domains, including nanocomposite materials, ${ }^{27}$ liquid crystals, ${ }^{28}$ stimuli-responsive hydrogels, ${ }^{29}$ quasi-solid electrolyte, ${ }^{30}$ (co-)photocatalysis, ${ }^{31-33}$ and molecular separation or storage. ${ }^{34-36}$
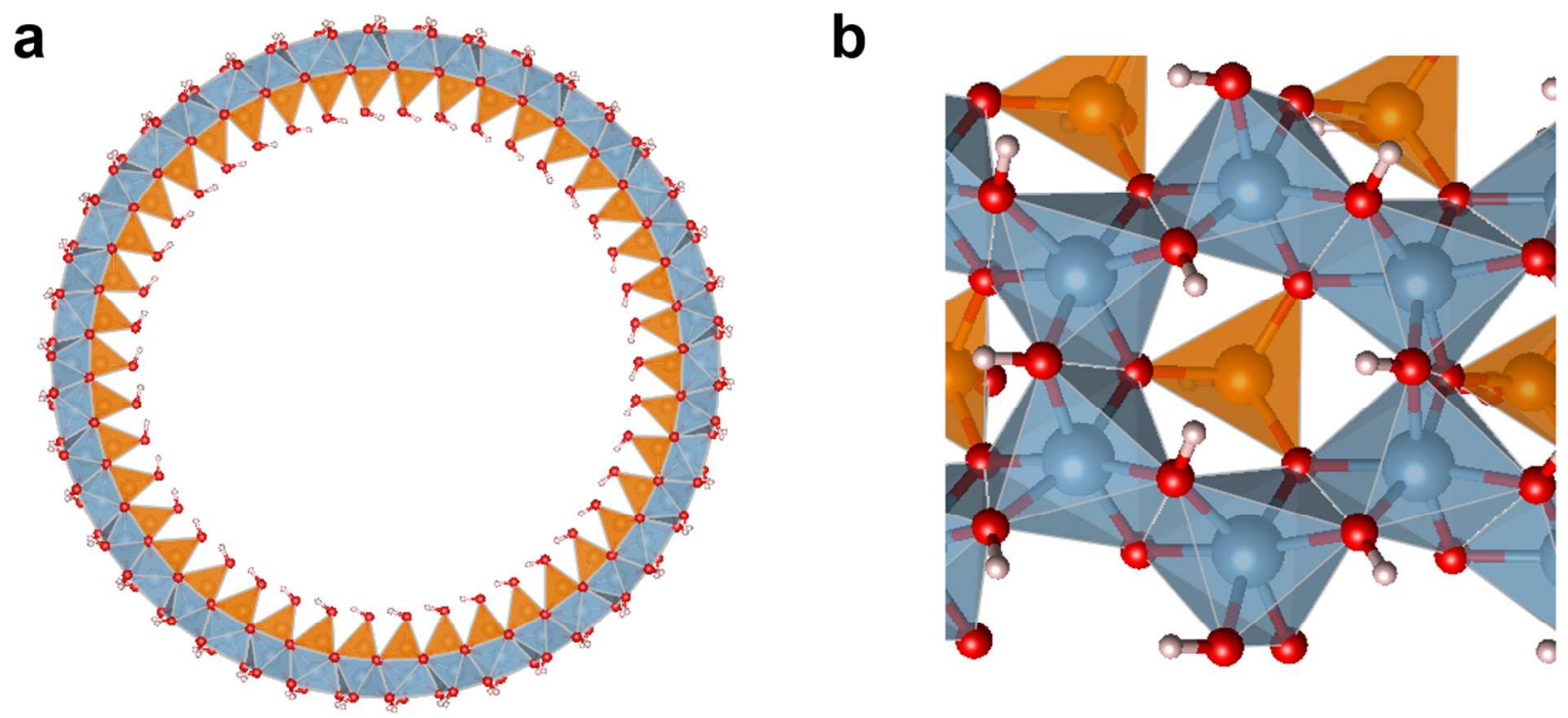

Figure 1. (a) Top and (b) side view of a single-walled imogolite nanotube. Al: blue; Si/Ge: orange; O: red; H: white.

However, for most of the intended application, a prerequisite remains the control of nanotubes arrangement in the solid state. Since the work of Wada \& Yoshinaga, ${ }^{37}$ electron 
micrographs revealed that imogolite can assemble in bundles in the solid state. ${ }^{4,7}$ Wada \& Henmi were the first to propose, to explain their porosity measurements, a hexagonal close packing (HCP) arrangement of imogolite nanotubes, implying the presence of intra- and inter-structureunit pores. ${ }^{38}$ The packing of INTs was considered to be hexagonal in most experimental, ${ }^{7,15,31,39}$ and simulation studies, ${ }^{40-42}$ though few works have also proposed that bundles of aluminosilicate and aluminogermanate INTs could have a two-dimensional (2D) monoclinic unit cell. ${ }^{11,26,43}$ Kang et al. highlighted that the best agreement with their experimental XRD results is obtained using either a bundle of 3 tubes in a hexagonal close packing or a bundle of four tubes with a monoclinic packing angle of $75^{\circ} .{ }^{44}$ Recently, Amara et al. clearly demonstrated that large bundles of INTs ( $\sim 60$ tubes) are arranged on a true hexagonal packing configuration, ${ }^{45}$ like for carbon $^{46}$ or other inorganic single-walled nanotubes. ${ }^{3}$

Despite this large literature, starting from aqueous suspensions of INT, the control of the formation of bundles in the dried state, as well as that of bundle size i.e. of the number of nanotubes within a bundle, is missing. It has been well recognized that, in soil contexts, imogolite has a large capacity to adsorb organic and inorganic anions depending on the $\mathrm{pH}$ and the ionic strength. ${ }^{47,48}$ In the case of synthetic nanotubes, ions initially present in the synthesis solution seem to be intercalated between the nanotubes in the solid state. ${ }^{15,49}$. Gustafsson ${ }^{50}$ put forward that a weak positive (negative) charge is developed on the outer (inner) surface of imogolite nanotubes, due to elongations and shortening in outer Al-O bond and inner Si-O ones, respectively lengths. It has further been corroborated by DFT simulations. ${ }^{19,51}$ Gustafsson proposed that the anions bind to parts of adjacent nanotubes, thereby explaining the formation of large INT bundles. ${ }^{50}$ Within this scope, nanotubes bundling could be controlled, in principle, by 
tuning the amount of residual salts in INT suspensions at the end of the synthesis process. To the best of our knowledge, this has never been investigated so far.

In this framework, we propose an experimental fresh look on the INT bundling by exploring the effect of the salt present in INT samples of synthetic aluminogermanate singlewalled imogolite nanotubes (Ge-SWINT). As true analogues of aluminosilicate nanotubes, GeSWINTs represent an ideal model system of the imogolite family, since they are synthesized with high concentrations, a necessary condition to probe directly INT organization in suspension. Characterization of the nanotube suspension is achieved by infrared (IR) and X-ray fluorescence (XRF) spectroscopy. Surface charge properties of Ge-SWINT are assessed thanks to electrophoretic measurements, revealing that the outer surface of Ge-SWINT is positively charged up to high $\mathrm{pH}$ values and hence, displays a strong affinity toward anions present in the suspension. The effect of salt on bundling of Ge-SWINT is investigated on suspensions with different ionic strengths (IS) as well as on powders obtained after evaporating the solvent. Bundling is analyzed thanks to X-ray scattering (XRS) experiments. Our experiments and their analysis allow us to propose the first phase diagram for the bundle assembling of metal-oxide imogolite nanotubes.

\section{EXPERIMENTAL SECTION}

Synthesis of Single-Walled Aluminogermanate Nanotubes (Ge-SWINT). Germanium (IV) ethoxide $\mathrm{Ge}(\mathrm{OEt})_{4}$, aluminum perchlorate $\mathrm{Al}\left(\mathrm{ClO}_{4}\right)_{3}$ and sodium hydroxide $\mathrm{NaOH}$ were purchased from Sigma Aldrich and were used as received. Ge-SWINT were synthesized using 
the perchlorate route described previously. ${ }^{45}$ By considering a complete conversion of precursors, the chemical reaction can be written as:

$$
\begin{aligned}
2 \mathrm{Al}_{\left(\mathrm{ClO}_{4}\right)_{3}+} & \mathrm{Ge}(\mathrm{OEt})_{4}+4 \mathrm{NaOH}+3 \mathrm{H}_{2} \mathrm{O} \\
& \rightarrow(\mathrm{OH})_{3} \mathrm{Al}_{2} \mathrm{O}_{3} \mathrm{Ge}(\mathrm{OH})+4 \mathrm{EtOH}+2 \mathrm{H}^{+}+4 \mathrm{Na}^{+}+6 \mathrm{ClO}_{4}{ }^{-}
\end{aligned}
$$

It consists in the co-precipitation under vigorous stirring of an aluminum perchlorate solution (1 mol. $\left.\mathrm{L}^{-1}\right)$ with $\mathrm{Ge}(\mathrm{OEt})_{4}$, followed by slow hydrolysis thanks to the addition of a $1 \mathrm{~mol} \cdot \mathrm{L}^{-1} \mathrm{NaOH}$ solution until a hydrolysis ratio $([\mathrm{OH}] /[\mathrm{Al}])$ of 2 is reached (Figure 2). The mixture is stirred overnight at room temperature in a Teflon beaker and then aged into an oven at $95{ }^{\circ} \mathrm{C}$ for 5 days. After cooling the reactor to ambient temperature, a whitish suspension is obtained, which will be referred to as $\mathrm{SW}_{\mathrm{ND}}\left(\mathrm{ND}=\right.$ not-dialyzed) hereafter. It is obvious from eq. (1) that $\mathrm{SW}_{\mathrm{ND}}$ suspension still contains a large number of ions $\left(\mathrm{H}^{+}, \mathrm{Na}^{+} \& \mathrm{ClO}_{4}{ }^{-}\right)$, as confirmed by the high ionic conductivity $\sigma$ of this suspension (Table 1). As shown by Amara et al., ${ }^{45}$ this protocol allows the synthesis of Ge-SWINT with a length $\sim 40-100 \mathrm{~nm}$ and monodisperse inner and outer diameters of $\sim 2.8$ and $4.1 \mathrm{~nm}$. 


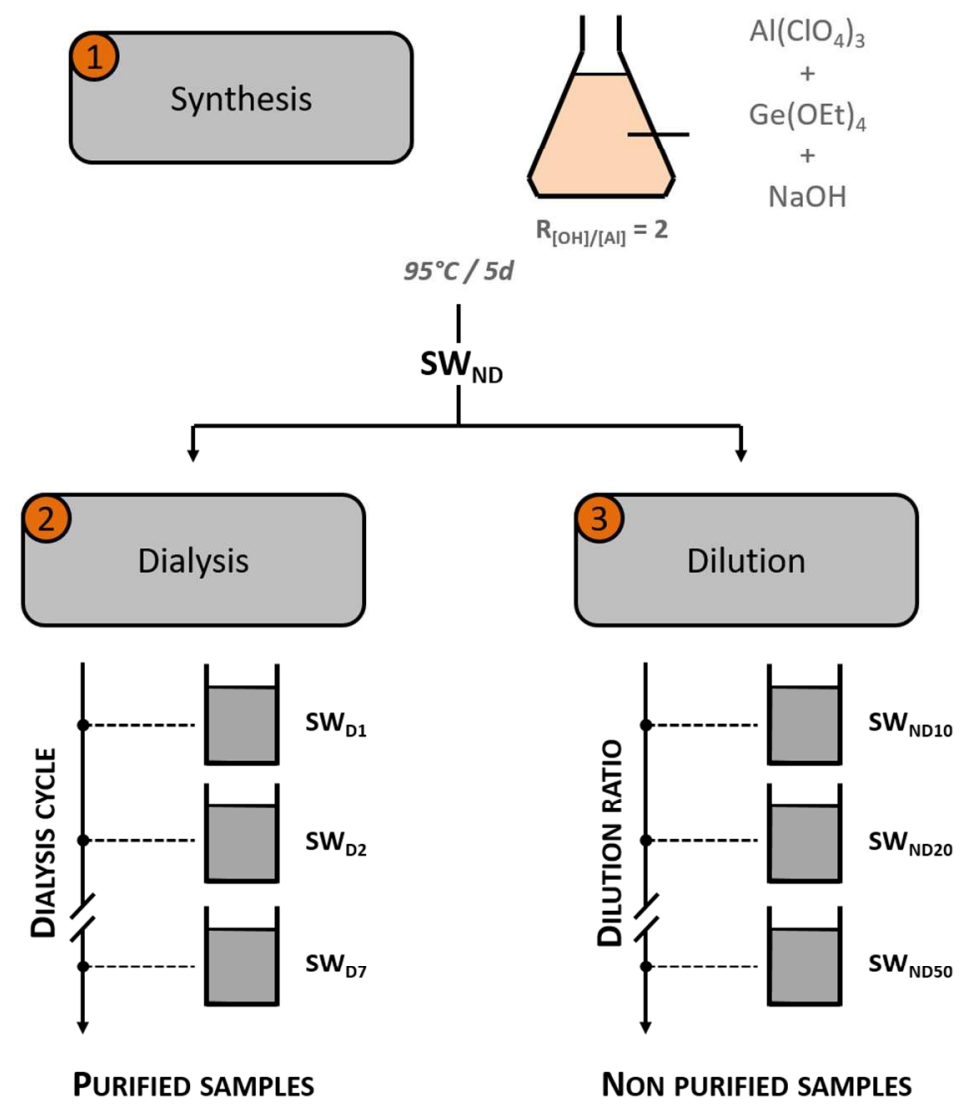

Figure 2. Flowchart for the synthesis of Ge-SWINT and samples preparation used in this study.

Table 1. pH, Conductivity and Ionic Strength (IS) ${ }^{a}$ Values Obtained for Dialyzed (SW DW $\left._{\mathbf{D} x}\right)$ and Non-Dialyzed $\left(\mathrm{SW}_{\mathrm{ND} y}\right)$ Samples. $x$ and $y$ Being Respectively the Number of Dialysis and the Dilution Ratio

\begin{tabular}{cccc}
\hline Name & $\mathrm{pH}$ & $\begin{array}{c}\text { Conductivity } \sigma \\
\left(\mathrm{mS} . \mathrm{m}^{-1}\right)\end{array}$ & $\begin{array}{c}\text { Ionic Strength } \\
\left(\mathrm{mol}^{-1}\right)\end{array}$ \\
\hline $\mathrm{SW}_{\mathrm{ND}}$ & 2.47 & 1800 & 0.14 \\
$\mathrm{SW}_{\mathrm{ND} 10}$ & 2.67 & n.d & $0.13^{\mathrm{b}}$ \\
$\mathrm{SW}_{\mathrm{ND} 20}$ & 2.71 & n.d & $0.11^{\mathrm{b}}$ \\
$\mathrm{SW}_{\mathrm{ND} 30}$ & 2.79 & n.d & $0.1^{\mathrm{b}}$ \\
$\mathrm{SW}_{\mathrm{ND} 40}$ & 2.85 & n.d. & $0.08^{\mathrm{b}}$ \\
$\mathrm{SW}_{\mathrm{ND} 50}$ & 2.92 & n.d & $0.07^{\mathrm{b}}$ \\
$\mathrm{SW}_{\mathrm{D} 1}$ & 3.41 & 55 & $6 \times 10^{-3}$ \\
$\mathrm{SW}_{\mathrm{D} 2}$ & 3.73 & 20 & $2 \times 10^{-3}$ \\
$\mathrm{SW}_{\mathrm{D} 3}$ & 4.25 & 10.5 & $10^{-3}$ \\
$\mathrm{SW}$ & 5.99 & 3.4 & $5 \times 10^{-4}$ \\
Ultrapure $_{\text {trater }}$ & $\sim 7$ & $\sim 0.0055$ & $\sim 10^{-7}$ \\
water & & &
\end{tabular}


${ }^{a}$ IS for dialyzed samples were calculated from $\sigma$ results (see text for details). ${ }^{b}$ estimated value based on the IS of $\mathrm{SW}_{\mathrm{ND}}$ suspension and the dilution ratio. n.d.: not determined.

Samples Preparation. In order to find out how residual ions can affect bundle formation, two sets of samples have been prepared from aliquots of $\mathrm{SW}_{\mathrm{ND}}$. The first series consists in suspensions dialyzed against ultrapure water (conductivity $\sigma=5.5 \times 10^{-3} \mathrm{mS} . \mathrm{m}^{-1}$ ), using $10 \mathrm{kDa}$ membranes (Visking) placed in a $1 \mathrm{~L}$ reservoir (Figure 2). By varying the number of dialysis steps $x(1 \leq x \leq 7)$, we expected a change in the final conductivity of the resulting aqueous suspension. These samples will be designated $\mathrm{SW}_{\mathrm{D} x}$ in the following (Table 1). We have also explored the effect of dilution of $\mathrm{SW}_{\mathrm{ND}}$ (Figure 2). The suspensions obtained with this method will be designated $\mathrm{SW}_{\mathrm{ND} y}$, hereafter the subscript $y$ value corresponding to the dilution ratio (\%). The $\mathrm{pH}$ and the conductivity, whenever possible, have been measured at $20^{\circ} \mathrm{C}$ (Table 1). Starting from the suspensions, dry powder samples $\left(p-\mathrm{SW}_{\mathrm{D} x} \& p-\mathrm{SW} \mathrm{ND}_{\mathrm{N}}\right)$ were obtained after drying at $60^{\circ} \mathrm{C}$ during $24 \mathrm{~h}$, the resulting sediments being milled in an agate mortar to obtain a fine powder.

Infrared Spectroscopy. Fourier Transform Infrared (FTIR) measurement was performed with a Nicolet iS50 FTIR spectrometer equipped with a $\mathrm{KBr}$ beamsplitter and a DTGS/KBr detector. IR spectrum was recorded at $4 \mathrm{~cm}^{-1}$ resolution in transmission mode in the 1300-400 $\mathrm{cm}^{-1}$ range. The measurement was performed on a $\mathrm{KBr}$ pressed pellet prepared by mixing $\sim 1.5$ $\mathrm{mg}$ of $\mathrm{SW}_{\mathrm{D} 7}$ powder with $150 \mathrm{mg}$ of potassium bromide.

X-Ray Fluorescence Spectroscopy. Laboratory X-ray fluorescence (XRF) spectroscopy has been performed on a prototype instrument developed at Laboratoire de Physique des Solides (Orsay, France). Description details of the instrument are provided elsewhere. ${ }^{52}$ Briefly, the Xray beam is delivered by a copper rotating anode generator $\left(\lambda_{\mathrm{Cu} \mathrm{K \alpha}}=1.5418 \AA\right)$ monochromatized by a multilayer optics and collimated with a pinhole $(100 \mu \mathrm{m}$-diameter aperture $)$ placed at the tip of the collimator. Both the multilayer optics and the collimator are under primary vacuum. 
Fluorescence detection is assured by a silicon drift diode detector (Ketek $\mathrm{GmbH}$ ) placed at 10 $\mathrm{mm}$ from the sample. Analysis of the XRF data has been performed using the PyMca software. ${ }^{53}$

Electrophoretic Measurements. Experiment was carried out with a Zetasizer Nano ZS (Malvern) at a wavelength of $632 \mathrm{~nm}$ in a folded capillary polycarbonate cell with gold electrodes. The potential applied between the electrodes was set around $150 \mathrm{~V}$. The electrophoretic mobility was measured at $25{ }^{\circ} \mathrm{C}$ on $\mathrm{SW}_{\mathrm{D} 7}$ aqueous suspension $\left(10 \mathrm{mg} \cdot \mathrm{L}^{-1}\right)$, which was previously brought to $\mathrm{pH}=4$ by adding a $0.1 \mathrm{M} \mathrm{HCl}$ solution. Small amounts of a $0.1 \mathrm{M}$ $\mathrm{NaOH}$ solution were added stepwise $\left(\Delta_{\mathrm{pH}} \sim 0.5\right)$ under stirring to measure the mobility as a function of $\mathrm{pH}$. After an equilibrium time of $1 \mathrm{~min}$, the electrophoretic mobility was determined.

Polarized Optical Microscopy. Polarized optical microscopy (POM) observations were performed on $\mathrm{SW}_{\mathrm{NDx}}$ suspensions. Samples were introduced into flat borosilicate capillaries (VitroCom, $0.2 \times 2 \mathrm{~mm}$ ) and stored vertically after flame-sealing. Optical images were obtained by an Olympus optical microscope (BX51-P) equipped with crossed polarizers and a CCD.

X-ray Scattering Measurements (XRS). XRS measurements on Ge-SWINT suspensions were performed on a molybdenum rotating anode generator $\left(\lambda_{\mathrm{Mo} \mathrm{K} \alpha}=0.711 \AA\right)$ equipped with a multilayer optics providing a monochromatic beam of $1 \times 1 \mathrm{~mm}^{2}$ at the sample position. A vacuum chamber placed behind the sample holder allows minimization of the small angle scattering signal from air. A MAR research X-ray sensitive $345 \mathrm{~mm}$ plate detector with $100 \mu \mathrm{m}$ pixel size is placed behind the output window of the vacuum chamber, at a distance of $720 \mathrm{~mm}$ from the sample. ${ }^{54}$ This setup allows us to reach scattering vectors down to $Q_{\min }=0.03$ $\AA^{-1}(Q=4 \pi / \lambda \sin (\theta)$, where $\lambda$ is the incident wavelength and $2 \theta$ is the scattering angle). Aqueous suspensions have been held in Kapton capillaries ( $2.1 \mathrm{~mm}$ internal diameter) that were sealed by polydimethylsiloxane (PDMS) caps to prevent solvent evaporation. XRS measurements on 
powder samples were carried out on a copper rotating anode generator $\left(\lambda_{\mathrm{Cu} \alpha \alpha}=1.5418 \AA\right)$ monochromatized with a multilayer optics. X-ray scattering diagrams were collected on a MAR research X-ray sensitive $345 \mathrm{~mm}$ plate detector with $150 \mu \mathrm{m}$ pixel size, placed at a sample-todetector distance of $300 \mathrm{~mm}$. A $10 \mu \mathrm{m}$ thick Al foil was wrapped around a few milligrams of INT powder, leading to a parallelepipedic sample, with its small side $(1 \mathrm{~mm})$ being parallel to the incident X-ray beam. Scattered intensity $I$ as a function of the scattering vector modulus $Q$ is obtained by angular integration over the 2D scattering patterns using homemade software. Data are corrected for water and empty cell (Kapton) scattering in the case of suspensions. In the case of powders, the aluminum foil does not display any diffraction peak in the $Q$-range studied here $\left(Q \leq 1 \AA^{-1}\right)$ since its first Bragg peak arises at $Q \approx 2.7 \AA^{-1}$. In both experiments, experimental resolution can be approximated by a Gaussian with Full-Width at Half Maximum (FWHM) $\sim 0.013 \AA^{-1}$.

\section{THEORETICAL METHOD}

X-ray Scattering Formalism. X-ray scattering is a powerful and non-destructive technique that has been widely used to characterize imogolite nanotubes. However, some analyses remained limited to a simple comparison with published references. With a view to achieving an accurate understanding of XRS experiments, this section summarizes the principles of the simulations used in this work. X-ray scattering allows sorting out the cross-section shape and dimensions of the nanotubes, and, if these are organized in bundles, the number of nanotubes per bundle. ${ }^{9,23,28,45,55,56}$ The scattered intensity is proportional to the squared modulus of the scattering amplitude, the latter corresponding to the Fourier transform of the electronic density of all atoms within the sample. However, in the low $Q$-range studied here $\left(Q<1 \AA^{-1}\right)$, a homogeneous approximation can be considered. For instance, the nanotube can be approximated 
by a homogeneous hollow cylinder ${ }^{23,45}$ (Figure 3 a) defined by its internal radius $R_{i}$, its external radius $R_{e}$ and its average electronic density $\rho_{I N T}$.
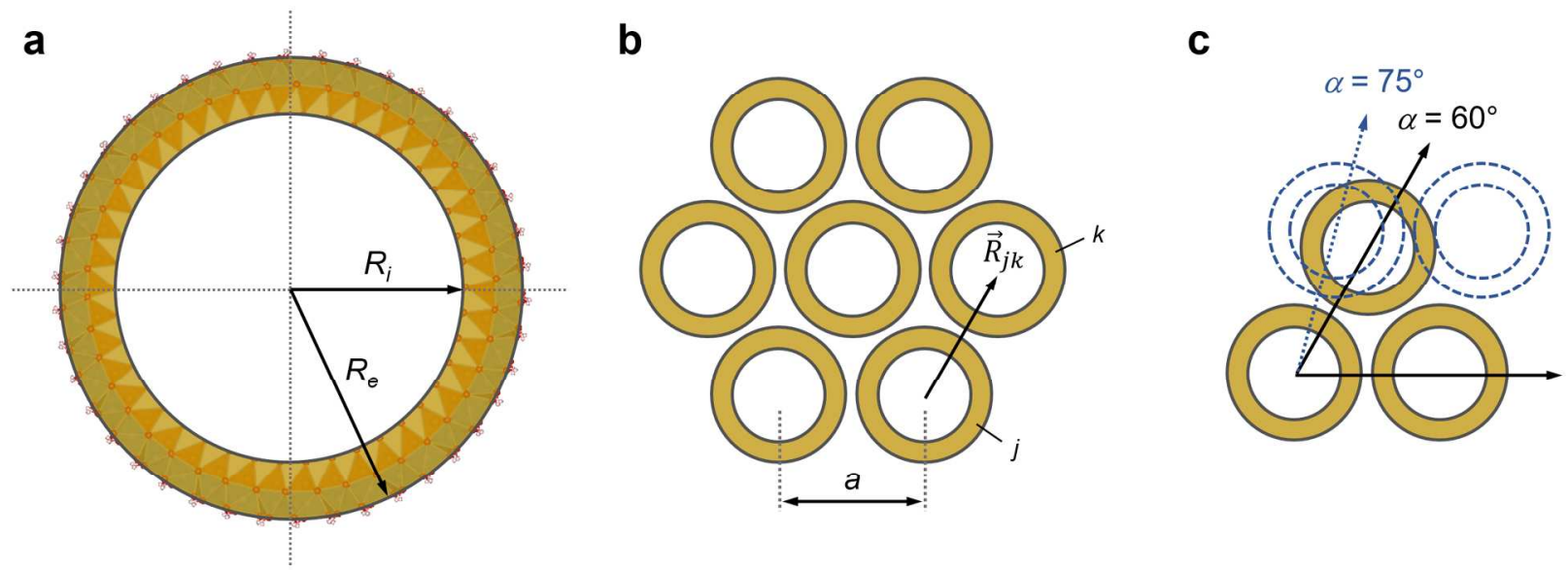

Figure 3. Schematic representations of: (a) a single-walled nanotube, in the homogeneous approximation, perpendicularly to its long axis; (b) nanotubes arranged on a 2D hexagonal lattice drawn in the plane perpendicular to the tubes axes; (c) hexagonal vs. monoclinic packing configuration.

We have shown recently that in first approximation, within experimental resolution, INTs can be approximated as infinite in length. ${ }^{45}$ The scattered intensity from non-bundled nanotubes of infinite length, with random orientations, simply writes:

$$
I(Q) \propto \frac{1}{Q} P(Q)^{2}
$$

where $P(Q)$ is the form factor of the nanotube defined as:

$$
P(Q)=\rho_{I N T} f_{I N T}(Q)\left(F_{R_{e}}(Q)-F_{R_{i}}(Q)\right)
$$

$F_{R}$ is the Fourier transform of cylinder disk of radius $R$ corresponding to the projection of a homogeneous nanotube along its axis: $F_{R}(Q) \propto \frac{R J_{1}(Q R)}{Q}$, with $J_{l}$ the cylindrical Bessel function of order 1. The X-ray form factor in eq. (3) is the normalized form factor of a $(\mathrm{OH})_{3} \mathrm{Al}_{2} \mathrm{O}_{3} \mathrm{Ge}(\mathrm{OH})$ 
unit $f_{I N T}(Q)=\frac{f_{G e}(Q)+2 f_{A l}(Q)+7 f_{O}(Q)+4 f_{H}(Q)}{118}, f_{i}(Q)$ being the X-ray form factor of atom $i$. For nanotubes in suspension, the form factor becomes: ${ }^{45}$

$$
P(Q)=\left(\rho_{I N T} f_{I N T}(Q)-\rho_{w} f_{w}(Q)\right)\left(F_{R_{e}}(Q)-F_{R_{i}}(Q)\right)
$$

$f_{w}(Q)=\frac{f_{O}(Q)+2 f_{H}(Q)}{10}$ being the normalized form factor of a water molecule, inside and outside the nanotubes, with $\rho_{w}=0.334 \mathrm{e}^{-} . \AA^{-3}$.

In the case of nanotubes organized in bundles (Figure 3b,c), we need to introduce an additional term called structure factor in the expression of the scattered intensity:

$$
I(Q) \propto \frac{1}{Q} P(Q)^{2} S(Q)
$$

where $S(Q)$ is the structure factor of the bundle defined as:

$$
S(Q)=\sum_{N b} p_{N_{b}} \sum_{j, k} J_{0}\left(Q R_{j k}\right)
$$

where the sum runs over all bundles formed by $N_{b}$ nanotubes, and on all nanotubes within the bundles. $\vec{R}_{j k}$ is the vector between the centers of the tube $j$ and $k$ in the bundle, in a plane perpendicular to the tube axis (Figure $3 \mathrm{~b}$ ). The term $p_{N_{b}}$ gives the proportion of each type of bundle in the sample and $J_{0}$ is the cylindrical Bessel function of order 0 . This equation is valid only for bundles in aqueous suspensions. For powder samples, we can no longer consider that water is homogeneously filling the space outside the nanotubes. Instead, we consider that a thin water cylinder surrounds each nanotube. In such a case, the expression of the scattered intensity becomes more complex than the simple one detailed in eq. (5) and (6). Equations are derived in Supporting Information, to avoid unbalancing the article with X-ray formalism.

Calculated XRS Diagrams. XRS diagrams corresponding to different degrees of bundling, calculated from eqs. (4) and (5), after convolution of the intensity to the resolution, are 
shown in Figure 4. The Ge-SWINT are characterized by the radii $R_{i}=13.8 \AA, R_{e}=20.3 \AA$ and the electronic density $\rho_{I N T}=0.74 \mathrm{e}^{-} . \AA^{-3}$, as determined previously. ${ }^{45}$ The grounds necessary for understanding XRS diagrams are discussed below.

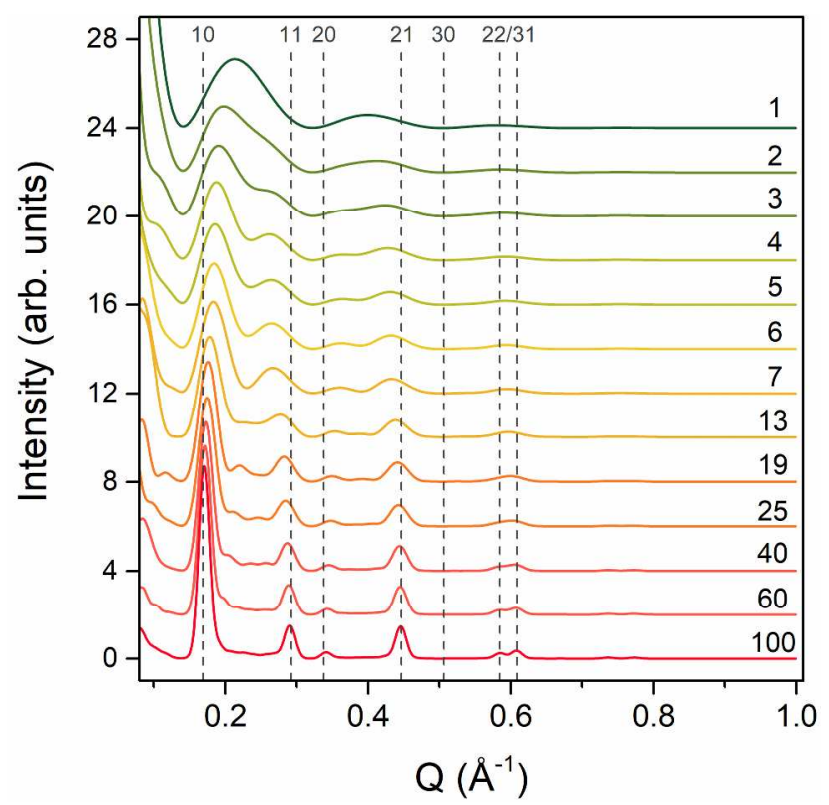

Figure 4. Simulated XRS diagrams for suspensions of bundles formed by $N_{b}$ tubes in hexagonal packing $(a=43 \AA)$. $N_{b}$ values, from 1 to 100 , are indicated in the figure. The $h k$ integers (dotted lines) index the reciprocal lattice nodes of an infinite hexagonal 2D lattice given in eq. (7). XRS curves have been translated vertically for the sake of clarity.

The XRS diagram of individual nanotubes $\left(N_{b}=1\right)$ displays large oscillations characteristic of the form factor of single-walled nanotubes (eq. (1)). At the opposite, the XRS diagrams of large bundles is formed of narrow peaks, coming from the structure factor term in eq. (5), which are resolution limited in width. Their positions are indexed by two Miller indices $h$ and $k$ :

$$
Q_{h k}=\sqrt{h^{2}+k^{2}+2 h k \cos (\alpha)} \frac{2 \pi}{a \sin (\alpha)}(7)
$$


where $a$ is the lattice parameter of the $2 \mathrm{D}$ lattice formed by the nanotubes; for $\alpha=60^{\circ}$, the $2 \mathrm{D}$ lattice is hexagonal while it is monoclinic for $\alpha \neq 60^{\circ}$ (Figure 3c). The decrease of the number of nanotubes per bundle induces a widening of these $h k$ peaks, as expected since correlation lengths decrease. Moreover, their positions shift towards the position of the closest maximum of the squared form factor, as expected from eq. (5). In this way, $Q_{10}$ and $Q_{20}$ increase while $Q_{11}$ and $Q_{21}$ decrease for decreasing number of INTs per bundle. ${ }^{57}$ It follows that the lattice parameter cannot be simply derived from the position of the 10 peak in the case of small bundles. Such a derivation would lead to an underestimation of $a$ of the order of $10 \%$ (Figure 4 ). ${ }^{57}$ This point, well-recognized in previous works on carbon nanotubes, ${ }^{55}$ appears still disregarded in the case of imogolite nanotubes. ${ }^{11,15,26}$ It may also be noted that conclusions concerning the packing angle $\alpha$ are not unambiguous when based on XRS from small bundles. ${ }^{44}$ It is illustrated in Figure 5, where calculated diffraction patterns involving either a monoclinic bundle with four tubes $\left(N_{b}=\right.$ 4, $\alpha=75^{\circ}$ ), a hexagonal one with three tubes $\left(N_{b}=3, \alpha=60^{\circ}\right)$ or a mixture with equal probabilities of hexagonal bundles $\left(N_{b}=2\right.$ and $\left.4, \alpha=60^{\circ}\right)$ are shown to give rather close diagrams. At the opposite, for large bundles, lattice characteristics can be easily obtained from eq. (7). 


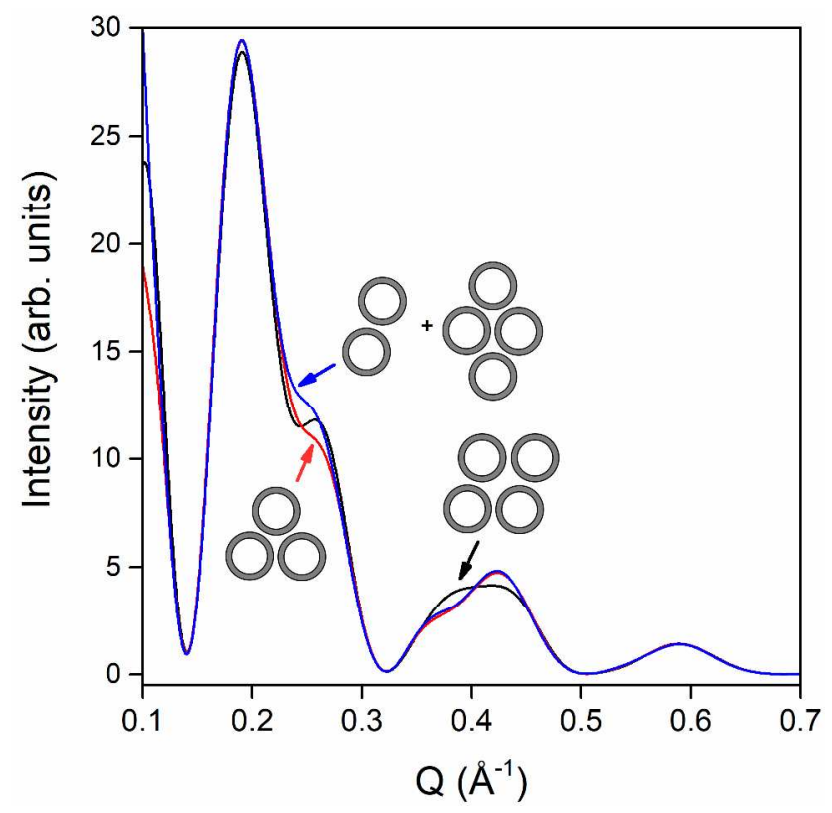

Figure 5. Calculated XRS diagrams of Ge-SWINT using eq. (5) for a monoclinic bundle (black curve, $N_{b}=4, \alpha=75^{\circ}$ ), a hexagonal bundle (red curve, $N_{b}=3, \alpha=60^{\circ}$ ) and a mixture with equal probabilities of hexagonal bundles (blue curve, $N_{b}=2$ and $4, \alpha=60^{\circ}$ ).

\section{RESULTS AND DISCUSSION}

Suspension Purity and Surface Properties of Ge-SWINT. Before investigating the effect of salt on bundling imogolite nanotubes, we first analyze the purity and surface properties of synthetic Ge-SWINT. This characterization step was performed on $\mathrm{SW}_{\mathrm{D} 7}$, i.e. the most dialyzed sample, by combining infrared (IR) and X-ray fluorescence (XRF) spectroscopy, as well as electrophoresis measurement. The IR spectrum (Figure 6a) displays several absorption bands characteristic of INT backbone below $1000 \mathrm{~cm}^{-1}$, as detailed in Table 2. The characteristic vibrational band of perchlorate anions ${ }^{15,23,49}$, located at $1100 \mathrm{~cm}^{-1}$, is also clearly visible. 

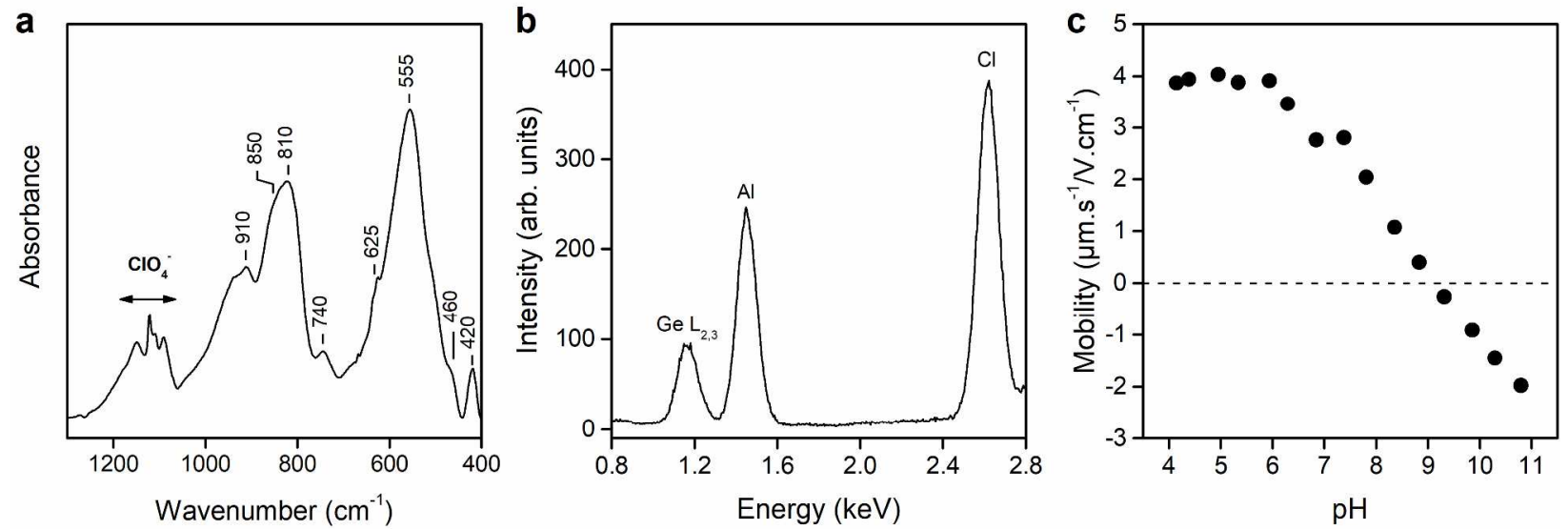

Figure 6. (a) Infrared and (b) X-Ray fluorescence spectra obtained on the $\mathrm{SW}_{\mathrm{D} 7}$ powder. (c) Electrophoretic mobility of a dilute $\mathrm{SW}_{\mathrm{D} 7}$ suspension $(0.1 \% \mathrm{w} / \mathrm{v})$ as a function of the $\mathrm{pH}$.

Table 2. Band Assignments ${ }^{23,45,49,58}$ ( $v$ : stretching; $\delta$ : bending) for Spectral Features Observed for Imogolite Backbone in the 1000-400 cm $^{-1}$ Range

\begin{tabular}{cc}
\hline Wavenumber $\left(\mathrm{cm}^{-1}\right)$ & Feature \\
\hline 910 & $\mathbf{G e - O}-\mathbf{A l} \mathbf{v}_{v}$ \\
850 & $\mathbf{G e}-\mathbf{O H}_{v}$ \\
810 & $\mathbf{G e - \mathbf { O } _ { v }}$ \\
740 & $\mathbf{A l - O H}$ \\
625 & $\mathbf{A l - \mathbf { O } _ { v }}$ \\
555 & $-\mathrm{OH}_{\delta}$ \\
460 & $\mathbf{G e - O}-\mathbf{A} \mathbf{l}_{\delta}$ \\
420 & $-\mathrm{OH}_{\delta} / \mathbf{G e -} \mathbf{O}_{\delta}$
\end{tabular}

Besides $\mathrm{Ge}$ and $\mathrm{Al}$ atoms, $\mathrm{XRF}$ measurement also reveals the presence of chlorine in the $\mathrm{SW}_{\mathrm{D} 7}$ sample (Figure 6b). It arises from residual perchlorate $\left(\mathrm{ClO}_{4}^{-}\right)$species already identified in the IR spectrum. Perchlorate anions are products of the chemical reaction (eq. (1)). Interestingly, the presence of $\mathrm{ClO}_{4}{ }^{-}$anions in carefully washed samples (conductivity of the dialysate $\leq 0.5 \mathrm{mS} . \mathrm{m}^{-}$ ${ }^{1}$ ) indicates that Ge-SWINT, like natural and synthetic Si-SWINT nanotubes, ${ }^{59,60}$ present a strong affinity towards ion adsorption. However, the electrostatic potential of Ge-SWINT had never been experimentally investigated up to now. We therefore assess the surface charge properties of Ge-SWINT by measuring the electrophoretic mobility of $\mathrm{SW}_{\mathrm{D} 7}$. Figure $6 \mathrm{c}$ reports the evolution 
of this mobility as a function of the $\mathrm{pH}$. For $\mathrm{pH}$ values higher than 7 , the mobility decreases linearly with $\mathrm{pH}$. The point of zero charge (pzc) is found at $\mathrm{pH}=9.5$ for $\mathrm{SW}_{\mathrm{D} 7}$, close to the values around 10 obtained previously for Si-SWINT. ${ }^{61,62}$ From $\mathrm{pH} 3$ to 6 , the mobility is constant and positive, indicating a positive outer surface charge. ${ }^{62}$ The samples obtained after dialysis or dilution of $\mathrm{SW}_{\mathrm{ND}}$ are in this $\mathrm{pH}$ range (Table 1). In a simple model, the ionic strength can be related to the conductivity $\sigma$ of the suspension by the relation:

$$
\sigma=\sum_{i}\left[X_{i}\right] \lambda_{i}
$$

where $\left[X_{i}\right]\left(\mathrm{mol} . \mathrm{m}^{-3}\right)$ and $\lambda_{i}\left(\mathrm{mS} \cdot \mathrm{m}^{2} \cdot \mathrm{mol}^{-1}\right)$ represent respectively the concentration and the limiting molar ionic conductivity of ion $i$. The ions species obtained after INT synthesis (see. eq. (1)) are $\mathrm{Na}^{+}, \mathrm{ClO}_{4}{ }^{-}$and $\mathrm{H}^{+}$with $\lambda_{i}$ values equal to 5, 6.7 and 35 , respectively. The ionic strength (IS) of the suspension is defined by the concentration of monovalent ions $\mathrm{ClO}_{4}{ }^{-}$anions since all ionic species are monovalent. For fully dialyzed suspension $\left(\mathrm{SW}_{\mathrm{D} 7}\right)$, it can be assumed that all $\mathrm{Na}^{+}$ions have been removed. Therefore, the ionic strength (IS) of the suspension can be deduced from its $\mathrm{pH}$ value using the following equation:

$$
[I S]=\frac{\sigma-10^{-p H} \lambda_{H^{+}}}{\lambda_{\mathrm{ClO}_{4}^{-}}}
$$

On the other hand, non-dialyzed suspensions still contain a large quantity of salt. In that case, we can neglect the (negative) counter ions of INT surface charge and assume that $\left[\mathrm{ClO}_{4}{ }^{-}\right]=$ $\left[\mathrm{Na}^{+}\right]+\left[\mathrm{H}^{+}\right]:$

$$
[I S]=\frac{\sigma-10^{-p H}\left(\lambda_{H^{+}}+\lambda_{\mathrm{ClO}_{4}^{-}}\right)}{\left(\lambda_{\mathrm{Na}^{+}}+\lambda_{\mathrm{ClO}_{4}}\right)}
$$

The estimated IS values of all samples have been reported in Table 1. In conclusion, we demonstrated here that the external surface of Ge-SWINTs is positively charged, allowing 
potentially anions condensation on these external surfaces at $\mathrm{pH}<6$, and that anions concentration depends on the purification process (Figure 2).

Effect of Ionic Strength on Bundling of Ge-SWINT in Suspensions. Depending on the nanotube aspect ratio and solvent ionic strength, different salt-modulated organization can be expected for charged 1D nanostructures..$^{28,63,64}$ In particular, it has been well recognized that assembly of polyelectrolytes, such as microtubules or actin filaments, can be controlled in suspension by long-range electrostatic interactions and form hexagonal bundles above a critical salt concentration. ${ }^{65-67}$ In the case of SWINT, the role of salts has also been proposed to explain the formation of imogolite bundles, but it has never been carefully investigated previously. The synthesis of Ge-SWINT being based on liquid-phase chemistry, we first investigated the effect of ionic strength on aqueous suspensions. Figure 7 presents the polarized optical microscopy (POM) images obtained on samples prepared by dilution of a high ionic strength suspension $\left(\mathrm{SW}_{\mathrm{ND}}\right)$.
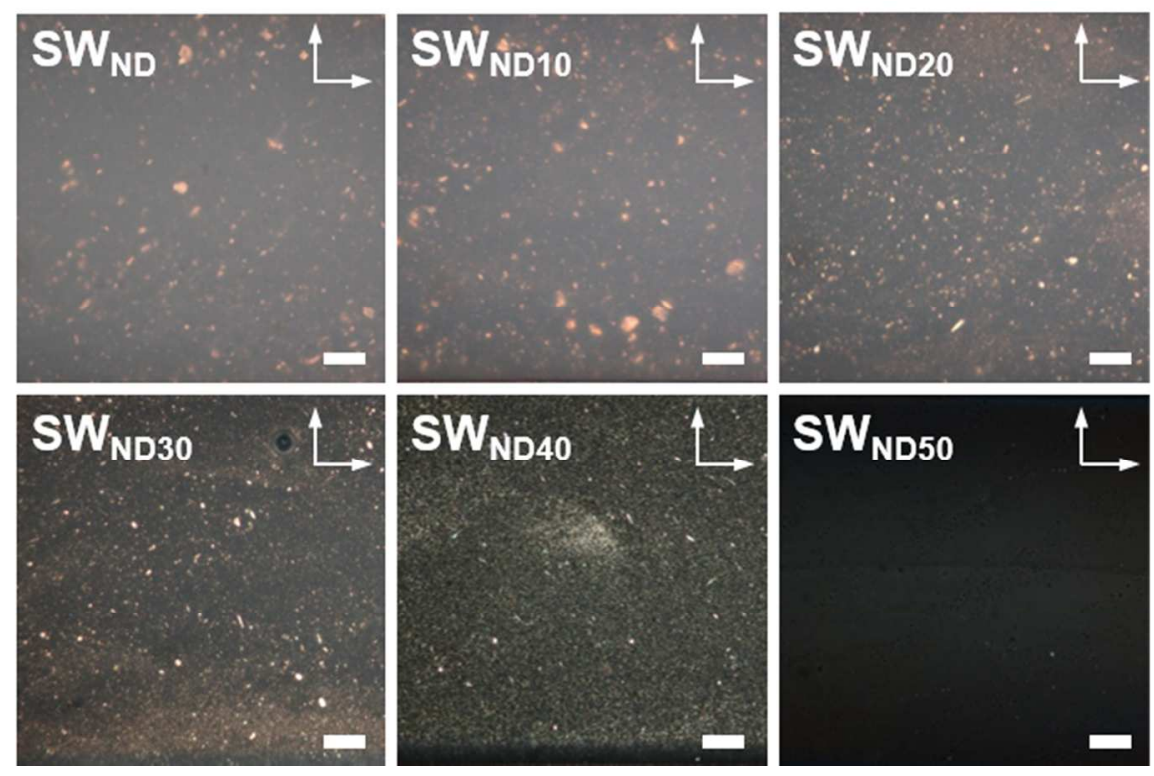
Figure 7. POM images of the suspensions prepared at different dilution ratios from $\mathrm{SW}_{\mathrm{ND}}$ suspension. The crossed polarizers are indicated by the white arrows. The scale bar represents $200 \mu \mathrm{m}$.

POM observations between crossed polarizers reveal the presence of large and birefringent domains, corresponding to aggregates of nanotubes. It is worth noting that these optical textures should not be confused with those observed recently in liquid-crystal phases of Ge-DWINT. ${ }^{28}$ We also noticed that the proportion of birefringent structures is reduced by increasing the dilution ratio. No more aggregates are observed for IS $<8 \times 10^{-2} \mathrm{~mol}^{-1}$ and the suspension presents an isotropic texture $\left(\mathrm{SW}_{\mathrm{ND} 50}\right.$, Figure 7).

These observations have been confirmed by XRS measurements and simulations (Figure 8a). Simulated XRS diagrams in Figure $8 \mathrm{a}$ were obtained using eq. (5), assuming that the measured intensity is the sum of the intensity from isolated nanotubes $\left(N_{b}=1\right)$, probably mainly in the suspension, and of the intensity from bundled ones $\left(N_{b}=60\right)$, in the birefringent aggregates. As mentioned before, the peaks related to the $2 \mathrm{D}$ hexagonal lattice are resolution limited in width and one could hardly discriminate between bundles with 60 tubes and larger bundle size. Therefore, we use a value of $N_{b}=60$ in our XRS simulations. As shown in section 3 , the narrow diffraction peaks in XRS diagrams give information about the nanotube packing in the aggregates. In our case, these peaks can all be indexed with a two-dimensional (2D) hexagonal lattice (Figure 8b). 

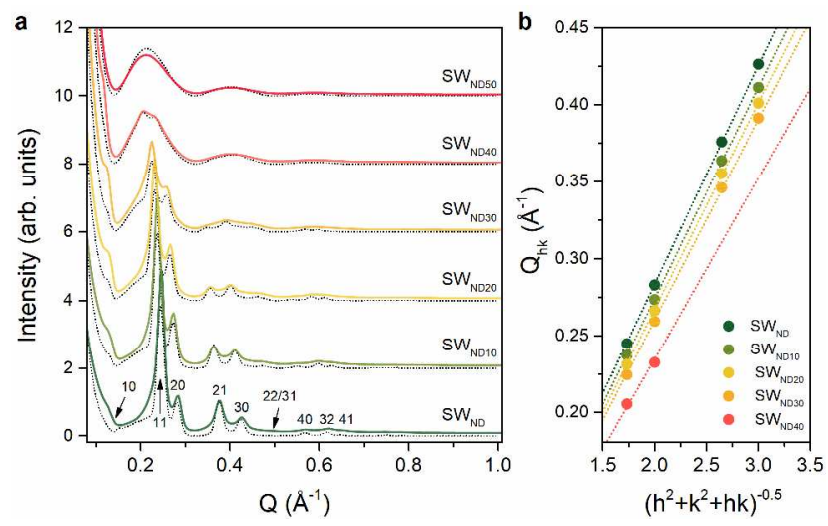

Figure 8. (a) Evolution of XRS diagrams of $\mathrm{SW}_{\mathrm{ND} y}$ suspension upon the dilution ratio $y$. Solid curves: experimental measurements; dotted curves: calculated XRS diagrams (see text for details). In both cases, the XRS curves have been translated vertically for the sake of clarity. (b) Plots of the $Q$ values of the $h k$ reflections vs. $\left(\mathrm{h}^{2}+\mathrm{k}^{2}+\mathrm{hk}\right)^{-0.5}$. The dotted lines obtained from eq. (7) illustrate the $2 \mathrm{D}$ hexagonal packing and allow one to determine the lattice parameter $a$.

'Measurements reveal a shift of the positions of the sharp reflections to lower $Q$-values with decreasing the ionic strength. This feature corresponds to an increase of the lattice parameter with increasing the dilution ratio (Table 3). The increase of the lattice parameter may be attributed to stronger electrostatic repulsion i.e. larger Debye length $\left(\kappa^{-1}=0.304 / \sqrt{[\mathrm{IS}]}\right){ }^{68}$ Accordingly, and in agreement with POM observations, simulations point toward a decrease of the proportion of bundles with the decrease of the ionic strength (Table 3).

Table 3. Values of the Lattice Parameter $a$ Calculated from eq. (5) and the Proportion $p$ of Large Bundles $\left(N_{b}=60\right)$ in Suspensions of $S_{N D y}$, Determined from the Best Fit of the XRS Curves Using eq. (5).

\begin{tabular}{ccccccc}
\hline & $\mathrm{SW}_{\mathrm{ND}}$ & $\mathrm{SW}_{\mathrm{ND} 10}$ & $\mathrm{SW}_{\mathrm{ND} 20}$ & $\mathrm{SW}_{\mathrm{ND} 30}$ & $\mathrm{SW}_{\mathrm{ND} 40}$ & $\mathrm{SW}_{\mathrm{ND} 50}$ \\
\hline$a(\AA)$ & 51.2 & 52.9 & 54.3 & 55.8 & 61.8 & - \\
$p(\%)$ & 7.1 & 5.3 & 2.8 & 0.8 & 0.1 & 0
\end{tabular}


Below an IS threshold of $8 \times 10^{-2} \mathrm{~mol} \cdot \mathrm{L}^{-1}$, the XRS curves are dominated by the form factor of a Ge-SWINT only $\left(\mathrm{SW}_{\mathrm{ND} 50}\right)$. This is also true for suspensions prepared by dialyses (Figure 9a), whose IS are below $6 \times 10^{-3}$ (Table 1). Whatever the number of washing steps $x$, the XRS diagrams of $\mathrm{SW}_{\mathrm{D} x}$ suspensions display similar regular oscillations, characteristics of $\mathrm{SW}$ nanotubes with no orientational nor positional correlations in the suspension. ${ }^{45}$
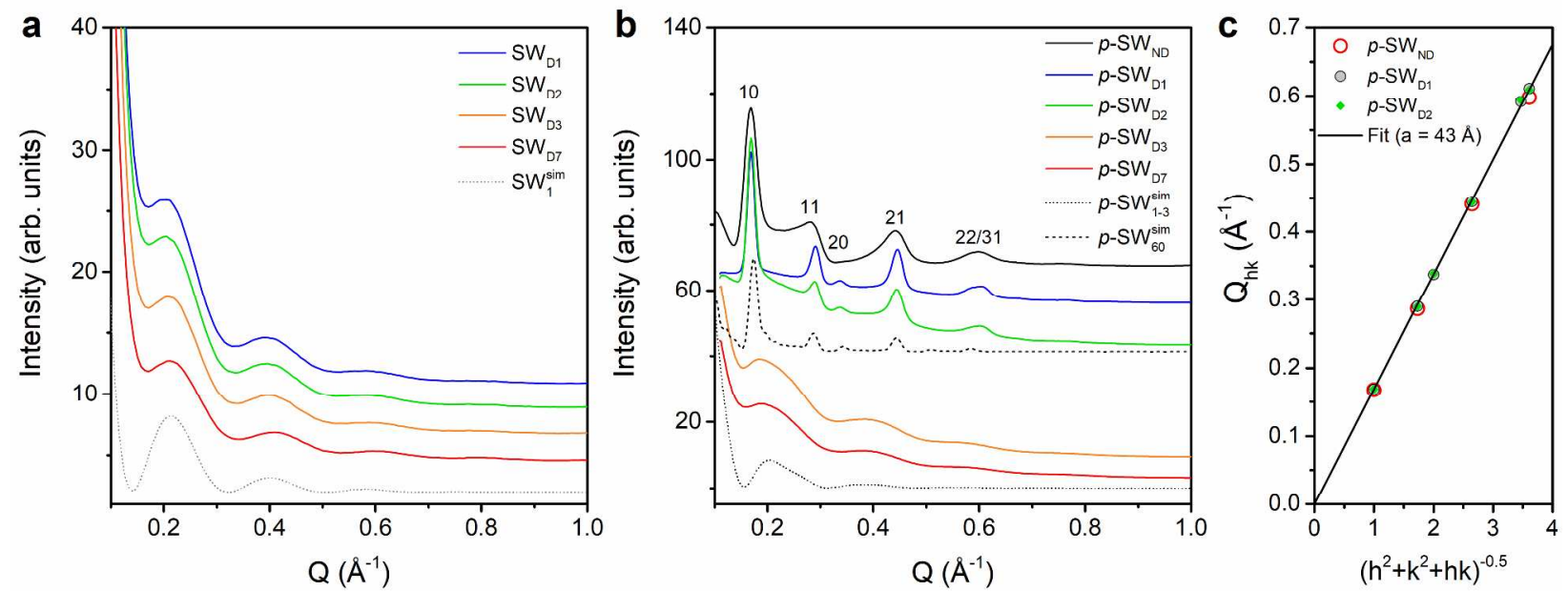

Figure 9. XRS diagrams of (a) $\mathrm{SW}_{\mathrm{D} x}$ suspensions and (b) $p-\mathrm{SW}_{\mathrm{D} x}$ after solvent evaporation at RT. For the sake of comparison, the XRS diagram on $p-\mathrm{SW}_{\mathrm{ND}}$ sample (not dialyzed) is also represented. The $h k$ integers index the reciprocal lattice nodes of a hexagonal 2D lattice. Dotted lines correspond to simulated XRS curves using eq. (S9) (see Supporting Information): SW $\left(N_{b}=1\right), \quad \operatorname{SW}_{1-3}^{\operatorname{sim}}\left(N_{b}=1, p=0.4 ; N_{b}=2, p=0.4 ; N_{b}=3, p=0.2, a=43 \AA ̊ \Omega\right), \quad \operatorname{SW}_{60}^{\operatorname{sim}}$ $\left(N_{b}=60, a=43 \AA\right.$ ). All curves have been translated vertically for the sake of clarity. (c) Plots of the $Q$ vectors of the $h k$ reflections of $p-\mathrm{SW}_{\mathrm{D} 1} \& p-\mathrm{SW}_{\mathrm{D} 2} \mathrm{vs} .\left(\mathrm{h}^{2}+\mathrm{k}^{2}+\mathrm{hk}\right)^{-0.5}$. The straight line obtained from eq. (7) illustrates the good agreement of the peak positions with a $2 \mathrm{D}$ hexagonal packing of the lattice parameter $a=43 \AA$.

Effect of Ionic Strength on Bundling of Ge-SWINT in Powders. In a second step, the measurements have been performed on powders of the same $\mathrm{SW}_{\mathrm{D} x}$ samples as those studied in 
suspension, after water evaporation (Figure $9 \mathrm{~b}$ ). XRS curves of $p-\mathrm{SW}_{\mathrm{D} x}$, where the prefix ' $p$ ' stands for 'powder', present strong differences and can be merged into two groups. For the most dialyzed samples $\left(x \geq 3\right.$, IS $\leq 10^{-3}$ mol. $\left.\mathrm{L}^{-1}\right)$, only a slight deformation of the first oscillation of $P(Q)^{2}$ is observed, which can be attributed to the presence of bundles with limited size (less than 4 tubes / bundle). ${ }^{23,44}$ Indeed, we show that in this case ( $p$-SW $\mathrm{SW}_{\mathrm{D} 3} \& p-\mathrm{SW}_{\mathrm{D} 7}$, Figure $\left.9 \mathrm{~b}\right)$, the best agreement between experiments and simulations is obtained considering individual $\left(N_{b}=1\right.$, $p=0.4)$, dimer $\left(N_{b}=2, p=0.4\right)$ and trimer $\left(N_{b}=3, p=0.2\right)$ nanotube arrangements. In contrast, for the less dialyzed samples $\left(p-\mathrm{SW}_{\mathrm{D} 1} \& p\right.$-SW $\left.\mathrm{SW}_{\mathrm{D} 2}\right)$, XRS diagrams exhibit narrow diffraction peaks, which measured widths are resolution limited, corresponding to more than 60 tubes per bundle as confirmed by XRS simulation (dotted curve $p$-SW 60 in in Figure $9 \mathrm{~b}$ ). The peak positions, obtained experimentally from $p-\mathrm{SW}_{\mathrm{D} 1}$ and $p-\mathrm{SW}_{\mathrm{D} 2}$ curves, fit well with a calculated value $a \sim 43 \AA$ (Figure 9c). It is worth noting that XRS diagram obtained for powder sample $p$ $\mathrm{SW}_{\mathrm{ND}}$, corresponding to the highest ionic strength in suspension, also exhibit a narrow 10 diffraction peak, the position of which is shifted to higher $Q$ values (Figure 9b) compared to those reported in suspension (Figure 8a). The presence of some wider peaks at larger $Q$ values is probably related to the pre-existence of aggregates of bundles in the suspension. Calculation using eq. (7) illustrates the good agreement of the peak positions with a $2 \mathrm{D}$ hexagonal packing of the lattice parameter $a=43$, like for $p-\mathrm{SW}_{\mathrm{D} 1} \& p-\mathrm{SW}_{\mathrm{D} 2}$ (Figure 9c).

Phase Diagrams of Bundles Formation. Using XRS experiments and simulations, we are able to propose a general picture of the bundle formation in Ge-SWINT. Figure 10 presents tentative 'phase diagrams' representing the evolution of the nanotube bundling as a function of ionic strength in suspension and after solvent evaporation. 

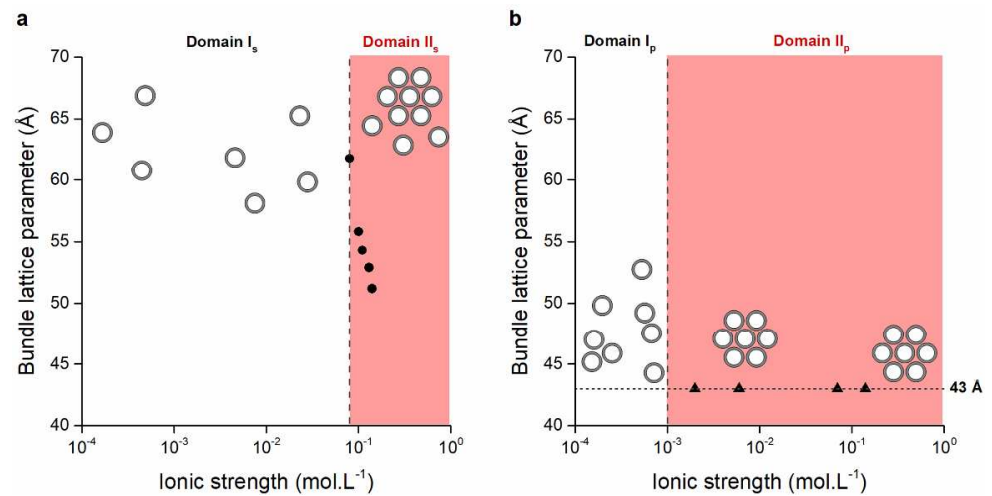

Figure 10. Phase diagrams (ionic strength/lattice parameter $a$ ) obtained for Ge-SWINT in (a) aqueous suspensions and (b) after solvent evaporation in dry state. Circle symbols correspond to the bundle lattice parameter obtained in aqueous suspensions while black triangles are related to those obtained in dry state. INT sketches represent the different Ge-SWINT organizations, deduced from XRS experiments and simulations.

We have clearly shown that all dialyzed samples $\left(\mathrm{SW}_{\mathrm{D} x}\right)$ consist in non-interacting nanotubes in aqueous suspension (Domain $\mathrm{I}_{\mathrm{s}}$ ) compared to non-purified $\mathrm{SW}_{\mathrm{NPy}}$ samples (up to $y$ $<50 \%$ ) which may contain large bundles greater than $\sim 60$ tubes/bundle (Domain $\mathrm{II}_{\mathrm{s}}$ ). Indeed, the decrease of ionic strength by dialysis, one dialysis step withdrawing more than $95 \%$ of residual salts (Table 1), implies a strong decrease of the Debye screening length. ${ }^{68}$ The influence of IS is particularly visible at high concentration, where a lowering of IS allows a disaggregation of Ge-SWINT bundles, in agreement with an increase of the Debye length. In aqueous suspensions, the transition between non-interacting nanotubes (Domain $\mathrm{I}_{\mathrm{s}}$ ) and bundles (Domain $\left.\mathrm{II}_{\mathrm{s}}\right)$ occurs for a critical value of IS $\sim 8 \times 10^{-2} \mathrm{~mol}_{\mathrm{L}}^{-1}\left(\kappa^{-1} \sim 1.1 \mathrm{~nm}\right)$. The bundle formation observed in dry state is also shown to depend on the amount of residual perchlorate anions, which condense on the outer surface of Ge-SWINT. During the solvent evaporation, these anions may screen the wall polarization, leading to a decrease of the electrostatic repulsion and the 
bundling of nanotubes, as suggested previously for aluminosilicate nanotubes Si-SWINT. ${ }^{47,48,50}$ In the case of Ge-SWINT, we have shown that a critical ionic strength of $10^{-3} \mathrm{~mol} \cdot \mathrm{L}^{-1}$ of the starting suspension is sufficient to form large bundles in dry state and that whatever the IS value, the bundle parameter is the same in powder ( $a \sim 43 \AA$, horizontal line in Figure 10b). Here, one may hypothesized that the lattice parameter value depends on the amount of residual water around the nanotubes, that is of the drying temperature. It is also important to underline that, even at low salt concentration (Domain $\mathrm{I}_{\mathrm{p}}$ in Figure 10b), nanotube separation as individual entities is actually quite difficult to achieve in powders and that it probably requires additional dialyses. These phase diagrams have been established for a given batch of Ge-SWINT. The general trends reported in Figure 10 should apply to all imogolite nanotubes. However, several factors could affect the wall polarization, namely the presence of defects, ${ }^{69,70}$ structures, modification of the shape (single- vs double-walled) or of the composition of the nanotube (Si/Ge atomic substitution). ${ }^{32,33}$ Such modifications of the surface charge properties of the INTs might modify the critical IS values between Domains $\mathrm{I}_{\mathrm{s}} \& \mathrm{II}_{\mathrm{s}}$ or $\mathrm{I}_{\mathrm{p}} \& \mathrm{II}_{\mathrm{p}}$.

In addition, the dependency on the ionic strength of the bundling tendency should also be tuned by the valence of the salts used to counter balance the surface charge of the nanotube. For instance, small-angle X-ray scattering measurements $\left(\mathrm{Q}<0.1 \AA^{-1}\right)$ performed on microtubules suspensions reveal that bundle size increases with increasing the valence of the counter ions. ${ }^{66}$ More experiments to investigate the role of defects or the nature of the salts would be interesting. On a theoretical background, the effect of electrostatic interactions is a complex many-body problem. In terms of interaction potential, slender cylinders are singular since their surface is highly curved, which makes an analytical approach difficult. This work should motivate future 
theoretical and simulation studies, which will allow one to get a better understanding of the competing electrostatic forces between INTs.

\section{CONCLUSIONS}

We have demonstrated in this work that the anion intercalation can control the bundling of aluminogermanate nanotubes. Electrophoretic mobility measurements performed on a suspension of Ge-SWINT allowed us to show that these nanotubes carry positive charges up to $\mathrm{pH}=9.5$ and are, thus, surrounded by anion shells. Analyses of XRS results through detailed simulations allow us to unravel different domains for nanotube organization. At low ionic strength (IS $<8 \times 10^{-2} \mathrm{~mol} \cdot \mathrm{L}^{-1}$ ), Ge-SWINTs are fully dispersed in aqueous suspensions due to strong electrostatic repulsion (large Debye screening length). However, higher salt concentrations induce aggregation phenomena in suspension, with a shrinking of the bundle lattice parameter with the increase of the concentration. After solvent evaporation, bundling in the dry state depends only, at the first-order, on the concentration of salt in the initial suspension. Ge-SWINT bundling in powder, characterized by the number $N_{b}$ of nanotubes in a bundle, varies beyond a critical ionic strength of $10^{-3}$ mol. $\mathrm{L}^{-1}$ from $N_{b}=1-3$ to $N_{b} \geq 60$, nanotubes being arranged on a true hexagonal packing configuration in large bundles. The approach proposed here also allows us to highlight the need for XRS simulations, especially in the case of small bundles. To conclude, our experimental findings attempt to give the first comprehensive view of bundling in metal-oxide nanotubes. We demonstrated that anions in the suspension can be used to tune nanotube arrangement. From a viewpoint of application development, these results suggest that a careful dialysis process is strongly recommended if the final application requires individual nanotubes instead of bundles. 


\section{ASSOCIATED CONTENT}

Supporting Information. Details of the formalism used to simulate X-ray scattering from bundles of nanotubes surrounded by a water cylinder. This is available free of charge via the Internet at http://pubs.acs.org.

\section{AUTHOR INFORMATION}

\section{Corresponding Author}

*E-mail: (E.P.) erwan-nicolas.paineau@u-psud.fr; (P.L.) pascale.launois@u-psud.fr

\section{ACKNOWLEDGMENTS}

M.S.A. benefited of a grant from the Domaine d'Intérêt Majeur (DIM) Nano'K under the network C'Nano Ile de France. We thank D. Petermann and O. Taché for technical assistance on X-ray diffractometers and S. Rols, G. Teobaldi, A. Thill and L. J. Michot for helpful discussions.

\section{REFERENCES}

(1) Iijima, S. Helical Microtubules of Graphitic Carbon. Nature 1991, 354 (6348), 56-58.

(2) Tenne, R. Inorganic Nanotubes and Fullerene-like Nanoparticles. Nat. Nanotechnol. 2006, $1,103-111$.

(3) Ni, B.; Liu, H.; Wang, P.; He, J.; Wang, X. General Synthesis of Inorganic Single-Walled Nanotubes. Nat. Commun. 2015, 6, 8756 .

(4) Wada, K.; Yoshinaga, N.; Yotsumoto, K.; Ibe, K.; Aida, S. High Resolution Electron Micrographs of Imogolite. Clay Miner. 1970, 8, 487-489. 
(5) Cradwick, P. D. G.; Farmer, V. C.; Russell, J. D.; Masson, C. R.; Wada, K.; Yoshinaga, N. Imogolite, a Hydrated Aluminium Silicate of Tubular Structure. Nature 1972, 240, 187189.

(6) Farmer, V. C.; Fraser, A. R.; Tait, J. M. Synthesis of Imogolite: A Tubular Aluminum Silicate Polymer. J. Chem. Soc. Chem. Commun. 1977, 13, 462-463.

(7) Barrett, S. M.; Budd, P. M.; Price, C. The Synthesis and Characterization of Imogolite. Eur. Polym. J. 1991, 27, 609-612.

(8) Levard, C.; Masion, A.; Rose, J.; Doelsch, E.; Borschneck, D.; Dominici, C.; Ziarelli, F.; Bottero, J.-Y. Synthesis of Imogolite Fibers from Decimolar Concentration at Low Temperature and Ambient Pressure: A Promising Route for Inexpensive Nanotubes. $J$. Am. Chem. Soc. 2009, 131, 17080-17081.

(9) Amara, M.-S.; Paineau, E.; Bacia-Verloop, M.; Krapf, M.-E. M.; Davidson, P.; Belloni, L.; Levard, C.; Rose, J.; Launois, P.; Thill, A. Single-Step Formation of Micron Long $(\mathrm{OH})_{3} \mathrm{Al}_{2} \mathrm{O}_{3} \mathrm{Ge}(\mathrm{OH})$ Imogolite-like Nanotubes. Chem. Commun. 2013, 49, 11284-11286.

(10) Chemmi, A.; Brendle, J.; Marichal, C.; Lebeau, B. Key Steps Influencing the Formation of Aluminosilicate Nanotubes by the Fluoride Route. Clays Clay Miner. 2015, 63, 132-143.

(11) Mukherjee, S.; Bartlow, V. A.; Nair, S. Phenomenology of the Growth of Single-Walled Aluminosilicate and Aluminogermanate Nanotubes of Precise Dimensions. Chem. Mater. 2005, 17, 4900-4909.

(12) Maillet, P.; Levard, C.; Larquet, E.; Mariet, C.; Spalla, O.; Menguy, N.; Masion, A.; Doelsch, E.; Rose, J.; Thill, A. Evidence of Double-Walled Al-Ge Imogolite-Like Nanotubes. A Cryo-TEM and SAXS Investigation. J. Am. Chem. Soc. 2010, 132, 12081209. 
(13) Avellan, A.; Levard, C.; Kumar, N.; Rose, J.; Olivi, L.; Thill, A.; Chaurand, P.; Borschneck, D.; Masion, A. Structural Incorporation of Iron into Ge-Imogolite Nanotubes: A Promising Step for Innovative Nanomaterials. RSC Adv. 2014, 4, 49827-49830.

(14) Shafia, E.; Esposito, S.; Manzoli, M.; Chiesa, M.; Tiberto, P.; Barrera, G.; Menard, G.; Allia, P.; Freyria, F. S.; Garrone, E.; Bonelli, B. Al/Fe Isomorphic Substitution versus $\mathrm{Fe}_{2} \mathrm{O}_{3}$ Clusters Formation in Fe-Doped Aluminosilicate Nanotubes (Imogolite). $J$. Nanoparticle Res. 2015, 17, 336.

(15) Zanzottera, C.; Vicente, A.; Armandi, M.; Fernandez, C.; Garrone, E.; Bonelli, B. Thermal Collapse of Single-Walled Alumino-Silicate Nanotubes: Transformation Mechanisms and Morphology of the Resulting Lamellar Phases. J. Phys. Chem. C 2012, 116, 23577-23584.

(16) Ma, W.; Otsuka, H.; Takahara, A. Poly(methyl Methacrylate) Grafted Imogolite Nanotubes Prepared through Surface-Initiated ARGET ATRP. Chem. Commun. 2011, 47, $5813-5815$.

(17) Shikinaka, K.; Abe, A.; Shigehara, K. Nanohybrid Film Consisted of Hydrophobized Imogolite and Various Aliphatic Polyesters. Polymer 2015, 68, 279-283.

(18) Bonini, M.; Gabbani, A.; Del Buffa, S.; Ridi, F.; Baglioni, P.; Bordes, R.; Holmberg, K. Adsorption of Amino Acids and Glutamic Acid-Based Surfactants on Imogolite Clays. Langmuir 2017, 33, 2411-2419.

(19) Guimaraes, L.; Enyashin, A. N.; Frenzel, J.; Heine, T.; Duarte, H. A.; Seifert, G. Imogolite Nanotubes: Stability, Electronic, and Mechanical Properties. ACS Nano 2007, 1, 362-368.

(20) Lourenco, M. P.; Guimaraes, L.; da Silva, M. C.; de Oliveira, C.; Heine, T.; Duarte, H. A. Nanotubes With Well-Defined Structure: Single- and Double-Walled Imogolites. J. Phys. Chem. C 2014, 118, 5945-5953. 
(21) Thill, A.; Guiose, B.; Bacia-Verloop, M.; Geertsen, V.; Belloni, L. How the Diameter and Structure of $(\mathrm{OH})_{3} \mathrm{Al}_{2} \mathrm{O}_{3} \mathrm{Si}_{\mathrm{x}} \mathrm{Ge}_{1-\mathrm{x}} \mathrm{OH}$ Imogolite Nanotubes Are Controlled by an Adhesion versus Curvature Competition. J. Phys. Chem. C 2012, 116, 26841-26849.

(22) Kang, D.-Y.; Brunelli, N. A.; Yucelen, G. I.; Venkatasubramanian, A.; Zang, J.; Leisen, J.; Hesketh, P. J.; Jones, C. W.; Nair, S. Direct Synthesis of Single-Walled Aminoaluminosilicate Nanotubes with Enhanced Molecular Adsorption Selectivity. Nat. Commun. 2014, 5, 3342.

(23) Amara, M. S.; Paineau, E.; Rouzière, S.; Guiose, B.; Krapf, M.-E. M.; Tache, O.; Launois, P.; Thill, A. Hybrid, Tunable-Diameter, Metal Oxide Nanotubes for Trapping of Organic Molecules. Chem. Mater. 2015, 27, 1488-1494.

(24) Yucelen, G. I.; Kang, D.-Y.; Guerrero-Ferreira, R. C.; Wright, E. R.; Beckham, H. W.; Nair, S. Shaping Single-Walled Metal Oxide Nanotubes from Precursors of Controlled Curvature. Nano Lett. 2012, 12, 827-832.

(25) Arancibia-Miranda, N.; Escudey, M.; Ramirez, R.; Gonzalez, R. I.; van Duin, A. C. T.; Kiwi, M. Advancements in the Synthesis of Building Block Materials: Experimental Evidence and Modeled Interpretations of the Effect of $\mathrm{Na}$ and $\mathrm{K}$ on Imogolite Synthesis. $J$. Phys. Chem. C 2017, 121, 12658-12668.

(26) Lee, H.; Jeon, Y.; Lee, Y.; Lee, S. U.; Takahara, A.; Sohn, D. Thermodynamic Control of Diameter-Modulated Aluminosilicate Nanotubes. J. Phys. Chem. C 2014, 118, 81488152.

(27) Ma, W.; Yah, W. O.; Otsuka, H.; Takahara, A. Application of Imogolite Clay Nanotubes in Organic-Inorganic Nanohybrid Materials. J. Mater. Chem. 2012, 22, 11887-11892. 
(28) Paineau, E.; Krapf, M.-E. M.; Amara, M.-S.; Matskova, N. V.; Dozov, I.; Rouzière, S.; Thill, A.; Launois, P.; Davidson, P. A Liquid-Crystalline Hexagonal Columnar Phase in Highly-Dilute Suspensions of Imogolite Nanotubes. Nat. Commun. 2016, 7, 10271.

(29) Shikinaka, K. Design of Stimuli-Responsive Materials Consisting of the Rigid Cylindrical Inorganic Polymer "imogolite.” Polym. J. 2016.

(30) Shikinaka, K.; Taki, N.; Kaneda, K.; Tominaga, Y. Quasi-Solid Electrolyte: A Thixotropic Gel of Imogolite and an Ionic Liquid. Chem. Commun. 2017, 53, 613-616.

(31) Shafia, E.; Esposito, S.; Armandi, M.; Bahadori, E.; Garrone, E.; Bonelli, B. Reactivity of Bare and Fe-Doped Alumino-Silicate Nanotubes (Imogolite) with $\mathrm{H}_{2} \mathrm{O}_{2}$ and the Azo-Dye Acid Orange 7. Catal. Today 2016, 277, 89-96

(32) Poli, E.; Elliott, J. D.; Ratcliff, L. E.; Andrinopoulos, L.; Dziedzic, J.; Hine, N. D. M.; Mostofi, A. A.; Skylaris, C.-K.; Haynes, P. D.; Teobaldi, G. The Potential of Imogolite Nanotubes as (Co-)Photocatalysts: A Linear-Scaling Density Functional Theory Study. $J$. Phys.-Condens. Matter 2016, 28, 074003.

Elliott, J. D.; Poli, E.; Scivetti, I.; Ratcliff, L. E.; Andrinopoulos, L.; Dziedzic, J.; Hine, N. D.; Mostofi, A. A.; Skylaris, C.-K.; Haynes, P. D. Chemically Selective Alternatives to Photoferroelectrics for Polarization $\square$ Enhanced Photocatalysis: The Untapped Potential of Hybrid Inorganic Nanotubes. Adv. Sci. 2016, 4, 1600153

(34) Kang, D.-Y.; Tong, H. M.; Zang, J.; Choudhury, R. P.; Sholl, D. S.; Beckham, H. W.; Jones, C. W.; Nair, S. Single-Walled Aluminosilicate Nanotube/Poly(vinyl Alcohol) Nanocomposite Membranes. ACS Appl. Mater. Interfaces 2012, 4, 965-976. 
(35) Zanzottera, C.; Armandi, M.; Esposito, S.; Garrone, E.; Bonelli, B. CO2 Adsorption on Aluminosilicate Single-Walled Nanotubes of Imogolite Type. J. Phys. Chem. C 2012, 116, $20417-20425$.

(36) Kang, D.-Y.; Lydon, M. E.; Yucelen, G. I.; Jones, C. W.; Nair, S. Solution-Processed Ultrathin Aluminosilicate Nanotube-Poly(vinyl Alcohol) Composite Membranes with Partial Alignment of Nanotubes. ChemNanoMat 2015, 1, 102-108.

(37) Wada, K.; Yoshinaga, N. The Structure of Imogolite. Am. Miner. 1969, 54, 50-71.

(38) Wada, K.; Henmi, T. Characterization of Micropores of Imogolite by Measuring Retention of Quaternary Ammonium Chlorides and Water. Clay Sci. 1972, 4, 127-136.

(39) Ackerman, W. C.; Smith, D. M.; Huling, J. C.; Kim, Y. W.; Bailey, J. K.; Brinker, C. J. Gas Vapor Adsorption in Imogolite - A Microporous Tubular Aluminosilicate. Langmuir 1993, 9, 1051-1057.

(40) Pohl, P. I.; Faulon, J. L.; Smith, D. M. Pore Structure of Imogolite Computer Models. Langmuir 1996, 12, 4463-4468.

(41) Creton, B.; Bougeard, D.; Smirnov, K. S.; Guilment, J.; Poncelet, O. Molecular Dynamics Study of Hydrated Imogolite. 1. Vibrational Dynamics of the Nanotube. J. Phys. Chem. C 2008, 112, 10013-10020.

(42) Zang, J.; Nair, S.; Sholl, D. S. Osmotic Ensemble Methods for Predicting AdsorptionInduced Structural Transitions in Nanoporous Materials Using Molecular Simulations. $J$. Chem. Phys. 2011, 134, 184103.

(43) Tamura, K.; Kawamura, K. Molecular Dynamics Modeling of Tubular Aluminum Silicate: Imogolite. J. Phys. Chem. B 2002, 106, 271-278. 
(44) Kang, D.-Y.; Zang, J.; Wright, E. R.; McCanna, A. L.; Jones, C. W.; Nair, S. Dehydration, Dehydroxylation, and Rehydroxylation of Single-Walled Aluminosilicate Nanotubes. ACS Nano 2010, 4, 4897-4907.

(45) Amara, M. S.; Rouzière, S.; Paineau, E.; Bacia-Verloop, M.; Thill, A.; Launois, P. Hexagonalization of Aluminogermanate Imogolite Nanotubes Organized into ClosedPacked Bundles. J. Phys. Chem. C 2014, 118, 9299-9306.

(46) Thess, A.; Lee, R.; Nikolaev, P.; Dai, H. Crystalline Ropes of Metallic Carbon Nanotubes. Science 1996, 273, 483.

(47) Clark, C. J.; McBride, M. B. Cation and Anion Retention by Natural and Synthetic Allophane and Imogolite. Clays Clay Miner. 1984, 32, 291-299.

(48) Su, C. M.; Harsh, J. B. The Electrophoretic Mobility of Imogolite and Allophane in the Presence of Inorganic Anions and Citrate. Clays Clay Miner. 1993, 41, 461-471.

(49) Farmer, V. C.; Fraser, A. R.; Tait, J. M. Characterization of the Chemical Structures of Natural and Synthetic Aluminosilicate Gels and Sols by Infrared Spectroscopy. Geochim. Cosmochim. Acta 1979, 43, 1417-1420.

(50) Gustafsson, J. P. The Surface Chemistry of Imogolite. Clays Clay Miner. 2001, 49, 73-80.

(51) Teobaldi, G.; Beglitis, N. S.; Fisher, A. J.; Zerbetto, F.; Hofer, A. A. Hydroxyl Vacancies in Single-Walled Aluminosilicate and Aluminogermanate Nanotubes. J. Phys.-Condens. Matter 2009, 21, 195301.

(52) Rouzière, S.; Jourdanneau, E.; Kasmi, B.; Joly, P.; Petermann, D.; Albouy, P. A. A Laboratory X-Ray Microbeam for Combined X-Ray Diffraction and Fluorescence Measurements. J. Appl. Crystallogr. 2010, 43, 1131-1133. 
(53) Solé, V. A.; Papillon, E.; Cotte, M.; Walter, P.; Susini, J. A Multiplatform Code for the Analysis of Energy-Dispersive X-Ray Fluorescence Spectra. Spectrochim. Acta Part B At. Spectrosc. 2007, 62, 63-68.

(54) Taché, O.; Rouzière, S.; Joly, P.; Amara, M.; Fleury, B.; Thill, A.; Launois, P.; Spalla, O.; Abécassis, B. MOMAC: A SAXS/WAXS Laboratory Instrument Dedicated to Nanomaterials. J. Appl. Crystallogr. 2016, 49, 1624-1631.

(55) Rols, S.; Almairac, R.; Henrard, L.; Anglaret, E.; Sauvajol, J.-L. Diffraction by Finite-Size Crystalline Bundles of Single Wall Nanotubes. Eur. Phys. J. B-Condens. Matter Complex Syst. 1999, 10, 263-270.

(56) Paineau, E.; Albouy, P.-A.; Rouzière, S.; Orecchini, A.; Rols, S.; Launois, P. X-Ray Scattering Determination of the Structure of Water during Carbon Nanotube Filling. Nano Lett. 2013, 13, 1751-1756.

(57) Rouzière, S.; Amara, M. S.; Paineau, E.; Launois, P. Deformations and Thermal Modifications of Imogolite. In Nanosized Tubular Clay Minerals; Developments in Clay Science; Elsevier; p 778.

(58) Martin, F.; Petit, S.; Grauby, O.; Lavie, M. P. Gradual H/D Substitution in Synthetic Germanium Bearing Talcs: A Method for Infrared Band Assignment. Clay Miner. 1999, $34,365-374$.

(59) Farmer, V.; Adams, M.; Fraser, A.; Palmieri, F. Synthetic Imogolite - Properties, Synthesis, and Possible Applications. Clay Miner. 1983, 18, 459-472.

(60) Harsh, J.; Traina, S.; Boyle, J.; Yang, Y. Adsorption of Cations on Imogolite and Their Effect on Surface-Charge Characteristics. Clays Clay Miner. 1992, 40, 700-706. 
(61) Arancibia-Miranda, N.; Escudey, M.; Molina, M.; Teresa Garcia-Gonzalez, M. Kinetic and Surface Study of Single-Walled Aluminosilicate Nanotubes and Their Precursors. Nanomaterials 2013, 3, 126-140.

(62) Rotoli, B. M.; Guidi, P.; Bonelli, B.; Bernardeschi, M.; Bianchi, M. G.; Esposito, S.; Frenzilli, G.; Lucchesi, P.; Nigro, M.; Scarcelli, V.; Tomatis, M.; Zanello, P. P.; Fubini, B.; Bussolati, O.; Bergamaschi, E. Imogolite: An Aluminosilicate Nanotube Endowed with Low Cytotoxicity and Genotoxicity. Chem. Res. Toxicol. 2014, 27, 1142-1154.

(63) Hoshino, H.; Urakawa, H.; Donkai, N.; Kajiwara, K. Simulation of Mesophase Formation of Rodlike Molecule, Imogolite. Polym. Bull. 1996, 36, 257-264.

(64) Tao, J.; Huang, N.; Li, J.; Chen, M.; Wei, C.; Li, L.; Wu, Z. Modulating the Arrangement of Charged Nanotubes by Ionic Strength in Salty Water. J. Phys. Chem. Lett. 2014, 5, $1187-1191$.

(65) Wong, G. C. L.; Lin, A.; Tang, J. X.; Li, Y.; Janmey, P. A.; Safinya, C. R. Lamellar Phase of Stacked Two-Dimensional Rafts of Actin Filaments. Phys. Rev. Lett. 2003, 91, 018103.

(66) Needleman, D. J.; Ojeda-Lopez, M. A.; Raviv, U.; Miller, H. P.; Wilson, L.; Safinya, C. R. Higher-Order Assembly of Microtubules by Counterions: From Hexagonal Bundles to Living Necklaces. Proc. Natl. Acad. Sci. U.S.A. 2004, 101, 16099-16103.

(67) Shikinaka, K.; Kwon, H.; Kakugo, A.; Furukawa, H.; Osada, Y.; Gong, J. P.; Aoyama, Y.; Nishioka, H.; Jinnai, H.; Okajima, T. Observation of the Three-Dimensional Structure of Actin Bundles Formed with Polycations. Biomacromolecules 2008, 9, 537-542.

(68) Israelachvili, J. N. Intermolecular and Surface Forces; Academic press, 2015. 
(69) Yucelen, G. I.; Choudhury, R. P.; Leisen, J.; Nair, S.; Beckham, H. W. Defect Structures in Aluminosilicate Single-Walled Nanotubes: A Solid-State Nuclear Magnetic Resonance Investigation. J. Phys. Chem. C 2012, 116, 17149-17157.

(70) Teobaldi, G.; Beglitis, N. S.; Fisher, A. J.; Zerbetto, F.; Hofer, W. A. Hydroxyl Vacancies in Single-Walled Aluminosilicate and Aluminogermanate Nanotubes. J. Phys.: Condens. Matter 2009, 21, 195301. 